\title{
Oxygen Cost of Walking in Hemiplegic Patients
}

\author{
Hiroshi Kuroki, MA, RPT ${ }^{1)}$, Toshiniro Morinaga, MS, RPT ${ }^{1)}$, Hiromichi Hama, PhD, MD ${ }^{1)}$ \\ ${ }^{1)}$ Division of Physical Therapy, College of Medical Technology, Kyoto University, 53 \\ Kawahara-cho, Shogoin, Sakyo-ku, Kyoto 606-01, Japan. TEL +81-75-751-3952. \\ FAX +81-75-751-3909.
}

\begin{abstract}
A preliminary study was carried out to compare the walking speed (WS), walking distance, oxygen consumption and oxygen cost in hemiplegic patients. In the first test of 10-min walking, observation of WS and walking distance revealed the boundary areas between the patients who depended on a wheelchair (group D, $\mathrm{n}=18$ ) and those who did not and could walk alone (group $\mathrm{I}, \mathrm{n}=26$ ). The boundary WS and boundary walking distance ranged from 20.1 to $30.0 \mathrm{~m} / \mathrm{min}$ and from 201 to 300 meters, respectively. In the second test which focused on the boundary WS, oxygen consumption and oxygen cost of groups TI (7 patients of group I), BI ( 5 of group I), BD (3 of group D) and TD (3 of group D) were measured. As a result, oxygen consumption and oxygen cost of TI, BI, BD and TD were13.6, $10.0,14.5$ and $10.0 \mathrm{ml} / \mathrm{kg} / \mathrm{min}$ and $0.351,0.358,0.628$ and $0.779 \mathrm{ml} / \mathrm{kg} / \mathrm{m}$, respectively. TI walked at a speed of more than $30.1 \mathrm{~m} / \mathrm{min}$, BI and BD walked at the boundary WS, and TD walked at a speed of less than $20.0 \mathrm{~m} / \mathrm{min}$. The values of oxygen cost differed remarkably between the groups BI and BD. BI walked more efficiently than BD.
\end{abstract}

Key words: Oxygen cost, Hemiplegia, Walking.

(This article was submitted Mar. 8, 1996, and was accepted May 20, 1996)

\section{INTRODUCTION}

The metabolic cost of walking has been described by several researchers. Bard ${ }^{1)}$ noted that it was important to consider energy expenditure of hemiplegic patients. Later, $\operatorname{Bard}^{2}$ ) indicated that there was a direct relationship between the degree of clinical spasticity and the metabolic cost of walking, and concluded that the cost of a comfortable speed of level walking was not particularly high in hemiplegic patients. Fisher ${ }^{3)}$ reported that hemiplegic patients required more energy to walk than normal subjects, but the data were quite variable. Mattsson ${ }^{4}$ defined oxygen cost as the amount of oxygen consumed per kilogram body mass per unit distance $(\mathrm{ml} / \mathrm{kg} / \mathrm{m})$. This parameter reflects efficiency of walking.

In hemiplegic patients who recover walking after a stroke, we can observe two types of patients, i.e. those who depend on a wheelchair and those who do not and can walk alone. The purpose of this preliminary study is to compare the walking speed (WS), oxygen consumption and oxygen cost between the two types of hemiplegic patients.

\section{METHODS}

\section{First test}

Forty-four hemiplegic patients (Table 1) participated in the first test. The patients met all of following criteria: 1) ability to walk without an attendant, 2) a history of unilateral cerebral vascular accident, 3) no complications of cardiac or pulmonary disease, 4) ability to understand procedure of the test, 5) agreement to participate in the test. No attempt was made to select the participants according to their degree of motor 
impairment.

The patients who depended on a wheelchair were classified as the dependent group (group D, $\mathrm{n}=18$ ) and those who did not and could walk alone were classified as the independent group (group I, n = 26).

The 44 patients were asked to walk on a $50 \mathrm{~m}$ long hospital corridor at their own pace for 10 consecutive minutes. They were also asked to stop walking when they felt fatigue, or if they became intolerant of continuous walking. In the walking test, 19 patients used a cane, 11 used a cane and an ankle-foot orthosis (AFO), 2 used a quad-cane and an AFO, 2 used an AFO, 1 used a forearm crutch and an AFO, 1 used a cane and a knee orthosis, and 8 used no walking aids.

Thirty five patients walked for 10 minutes and the remaining 9 ( 3 in group I and 6 in group D) stopped walking ( 2 at 7 minutes, 5 at 8 minutes and 2 at 9 minutes after the beginning of the test). However, all of the data of the 9 patients were considered valid because the patient's ability to walk was represented in the consecutive walking distance. Both the WS and the walking distance differed significantly between the two groups $(p<0.01)$. The mean of WS and walking distance of groups I and D were 35.8 and $13.3 \mathrm{~m} / \mathrm{min}$, and 350.2 and 121.4 meters, respectively. Observation of the results (Table 2) revealed that the boundary areas for WS and walking distance between the groups ranged from 20.1 to $30.0 \mathrm{~m} / \mathrm{min}$ and from 201 to $300 \mathrm{~m}$, respectively.

\section{Second test}

In the second test, oxygen consumption was

Table 1. Characteristics of all patients

\begin{tabular}{lrc}
\hline Sex; & male & 24 \\
& female & 20 \\
Age $(\mathrm{yr})$ & & $59.8 \pm 10.3$ \\
Body weight $(\mathrm{kg})$ & $50.5 \pm 7.2$ \\
Body height $(\mathrm{cm})$ & & $153.8 \pm 8.5$ \\
Diagnosis; & injury & 24 \\
& hemorrhage & 19 \\
affected side; & infarction & 19 \\
& right & 25 \\
Mean months after stroke (mo) & 38.3
\end{tabular}

(number or mean $\pm \mathrm{SD}$ ) measured and oxygen cost was calculated.

Eighteen of the 44 patients agreed to participate in the second test (12 patients of group I and 6 of group D). Their age, sex, anthropometric data, diagnosis, affected side and stages of motor recovery5) are presented in Table 3. Based on the WS of the first test, we classified 7 patients of group I as true-independent group (group TI) because they walked at a speed of more than $30.1 \mathrm{~m} /$ min, 5 patients of group I as boundary-independent group (group BI) because they walked at the boundary speed, 3 patients of group D as boundary-dependent group (group BD) because they walked at the boundary speed and 3 patients as true-dependent group (group TD) because they walked at a speed of less than $20.0 \mathrm{~m} / \mathrm{min}$.

The 12 patients underwent a preliminary walking test and, on the following day, a main walking test for 10 minutes. They were asked to walk using a similar protocol to that of the first test.

The gas expired during the last $5 \mathrm{~min}$ of the main walking test was collected in a Douglas bag. Its volume was corrected to the value of STPD (standard temperature, pressure and dry) and its composition was analyzed with a gas analyzer (NEC San-ei Co., Ltd, model 1H21A). The oxygen cost was calculated as oxygen consumption divided by WS. The temperature of the room was maintained at $25.1 \pm 2.3^{\circ} \mathrm{C}$.

One way analysis of variance (ANOVA) was used to determine the significance of differences in WS, oxygen consumption and oxygen cost among the four groups.

Table 2. Number of cases for a given range of walking speed and walking distance

\begin{tabular}{rcc}
\hline & group I & group D \\
\hline Walking speed (m/min) & & \\
-10.0 & & 6 \\
$10.1-20.0$ & 9 & 9 \\
$20.1-30.0$ (boundary area) & 12 & \\
$30.1-40.0$ & 5 & \\
$40.1-$ & & \\
Walking distance (m) & & 9 \\
$101-100$ & & 7 \\
$201-300$ (boundary area) & 11 & 2 \\
$301-400$ & 10 & \\
$401-$ & 5 & \\
\hline
\end{tabular}




\section{RESULTS}

WS, oxygen consumption and oxygen cost differed significantly among the four groups (Table $3)$.

The mean values of WS of the groups TI, BI, BD and TD were 39.9, 28.1, 23.2 and $12.9 \mathrm{~m} / \mathrm{min}$, respectively.

The mean values of oxygen consumption of the four groups were 13.6, 10.0, 14.5 and $10.0 \mathrm{ml} / \mathrm{kg}$ / min, respectively.

The mean values of the oxygen cost were 0.351 , $0.358,0.628$ and $0.779 \mathrm{ml} / \mathrm{kg} / \mathrm{m}$, respectively.

\section{DISCUSSION}

WS is specially important when we consider the patient's ability to walk ${ }^{6) 7}$. It is well known that WS is a reliable, objective and useful index of recovery of walking after a stroke ${ }^{8) 9}$. WS is also correlated with the functional category ${ }^{10)}$ and with walking independence, i.e. the requirement for assistance or supporting devices ${ }^{11)}$.

In the first test of the present study, no patient of group D walked at a speed of more than $30.1 \mathrm{~m} /$ min (Table 2). Similarly, no patient of group I walked at a speed of less than $20.0 \mathrm{~m} / \mathrm{min}$. These results demonstrate that WS is related to the difference between the two groups.

In the boundary area of the groups, however, the difference was not obvious only by WS. In our second test, WS was not so different between the groups BI and BD.

Measurement of oxygen consumption revealed that the patients of group TI, despite of the highest class of WS, consumed more oxygen than those of group BI and TD. On the other hand, the patients of group TD consumed less oxygen than those of groups TI and BD. The patients of groups TI and $\mathrm{BD}$ or groups BI and TD consumed an almost equal amount of oxygen per minute. To some extent, measurement of oxygen consumption revealed the difference between the groups BI and BD. However, the same difference existed between the groups TI and BI or the groups BD and TD.

Between the groups $\mathrm{BI}$ and $\mathrm{BD}$, oxygen cost was quite different (nearly twice). The value of group BI was 0.358 and that of BD was $0.628 \mathrm{ml} /$ $\mathrm{kg} / \mathrm{m}$. There was no significant differences between the groups TI and BI or groups BD and TD.

These results indicated that the difference between the groups BI and BD was not revealed only by WS or oxygen consumption but by oxygen cost.

Table 3. Results of measurement and comparison of anthropometric and clinica1 data

\begin{tabular}{|c|c|c|c|c|c|}
\hline & \multicolumn{2}{|c|}{ group I } & \multicolumn{2}{|c|}{ group D } & \\
\hline & $\mathrm{TI}(\mathrm{n}=7)$ & $\mathrm{BI}(\mathrm{n}=5)$ & $\mathrm{BD}(\mathrm{n}=3)$ & $\mathrm{TD}(\mathrm{n}=3)$ & \\
\hline male & 4 & 1 & 3 & & \\
\hline female & 3 & 4 & & 3 & \\
\hline Age (yr) & $57.6 \pm 12.0$ & $59.2 \pm 14.5$ & $64.3 \pm 7.5$ & $65.0 \pm 4.6$ & NS* \\
\hline Body weight (kg) & $50.9 \pm 6.8$ & $46.4 \pm 7.1$ & $49.0 \pm 5.3$ & $51.7 \pm 4.7$ & $\mathrm{NS} *$ \\
\hline Body height (cm) & $153.7 \pm 7.0$ & $148.2 \pm 8.5$ & $155.7 \pm 3.2$ & $148.7 \pm 6.0$ & NS* \\
\hline Diagnosis; & & & & & \\
\hline hemorrhage & 4 & 5 & 2 & 1 & \\
\hline infarction & 3 & & 1 & 2 & \\
\hline Affected side; $\quad$ right & 1 & 2 & 3 & 1 & \\
\hline left & 6 & 3 & & 2 & \\
\hline MRS**; & 1 & & 2 & 1 & \\
\hline 4 & 1 & 2 & 1 & 2 & \\
\hline 5 & 4 & 2 & & & \\
\hline 6 & 1 & 1 & & & \\
\hline Walking speed $(\mathrm{m} / \mathrm{min})$ & $39.9 \pm 8.8$ & $28.1 \pm 1.7^{\mathrm{a}, \mathrm{b}}$ & $23.2 \pm 1.7^{\mathrm{a}}$ & $12.9 \pm 3.0^{\mathrm{a}}$ & \\
\hline Oxygen consumption (ml/kg/min) & $13.6 \pm 2.5$ & $13.6 \pm 2.5^{\mathrm{c}, \mathrm{d}}$ & $13.6 \pm 2.5$ & $13.6 \pm 2.5^{\mathrm{c}, \mathrm{d}}$ & \\
\hline Oxygen cost $(\mathrm{ml} / \mathrm{kg} / \mathrm{m})$ & $0.351 \pm 0.078$ & $0.358 \pm 0.104$ & $0.628 \pm 0.048^{\mathrm{a}, \mathrm{e}}$ & $0.779 \pm 0.048^{\mathrm{a}, \mathrm{e}}$ & \\
\hline
\end{tabular}

NS*: not significant, MRS**: motor recovery stage ${ }^{8)},{ }^{a}: \mathrm{p}<0.01$ to TI, ${ }^{\mathrm{b}}: \mathrm{p}<0.01$ to TD, ${ }^{\mathrm{c}}: \mathrm{p}<0.05$ to TI, d: $\mathrm{p}<0.05$ to $B D, e: p<0.01$ to $B I$. 
Oxygen cost is the parameter which reflects the efficiency of walking. Mattsson ${ }^{4}$ described that measurements of walking speed and oxygen cost of level walking were found to be useful objective parameters for assessing walking and also to be a valuable supplement to clinical assessment of effects of treatment in patients with walking disorders.

Although the small number of subjects in the present study warrants further measurement of WS, oxygen consumption and oxygen cost in hemiplegic patients, it is supposed that, at the boundary WS, a difference on efficiency of walking appeared between the groups BI and BD.

\section{Aknowledgements}

The authors thank O.T.R. Kyoji Fujita, Mrs. Masae Kato and Mr. Takanori Yoshizawa for their help on data collection.

\section{REFERENCES}

1) Bard G, et al: Measurement of energy expenditure during ambulation, with special reference to evaluation of assistive devices. Arch Phys Med Rehabil 40: 415-420, 1959.

2) Bard G: Energy expenditure of hemiplegic subjects during walking. Arch Phys Med Rehabil 44: 368-
370, 1963.

3) Fisher SV, Gullickson G: Energy cost of ambulation in health and disability: a literature review. Arch Phys Med Rehabil 59: 124-133, 1978.

4) Mattsson E: Energy cost of level walking. Scand J Rehabil Med (Suppl) 23: 1-48, 1989.

5) Brunnstrom S: Movement Therapy in Hemiplegia: Neurophysiological Approach. New York, Harper \& Row, 1970, pp 34-55.

6) Mizrahi J, et al: Variation of time-distance parameters of the stride as related to clinical gait improvement in hemiplegics. Scand J Rehabil Med 14:133-140, 1982.

7) Mizrahi J, et al: Objective expression of gait improvement of hemiplegics during rehabilitation by time-distance parameters of the stride. Med Biol Eng Comput 20: 628-634, 1982.

8) Wade DT, et al: Walking after stroke: measurement and recovery over the first 3 months. Scand J Rehabil Med 19: 25-30 1987.

9) Friedman PJ: Gait recovery after hemiplegic stroke. Int Disabil Stud 12: 119-122, 1990.

10) Holden MK, et al: Gait assessment for neurologically impaired patients: standards for outcome assessment. Phys Ther 66: 1530-1539, 1986.

11) Bohannon RW: Gait performance of hemiparetic stroke patients: selected variables. Arch Phys Med Rehabil 68: 777-781, 1987. 